\title{
Commentary: Stents or surgery for chronic type-B dissection
}

\author{
Aamir Shah, MD, and Joanna Chikwe, MD
}

From the Department of Cardiac Surgery, Smidt Heart Institute, Cedars-Sinai Medical Center, Los Angeles, Calif. Disclosures: Cedars-Sinai Medical Center receives honoraria for speaker and other activities from Edwards Lifesciences and Medtronic.

Received for publication Oct 8, 2019; revisions received Oct 8, 2019; accepted for publication Oct 9, 2019; available ahead of print Oct 24, 2019.

Address for reprints: Joanna Chikwe, MD, Department of Cardiac Surgery, Smidt Heart Institute, Cedars-Sinai Medical Center, Los Angeles, CA 90048 (E-mail: Joanna.Chikwe@ cshs.org).

J Thorac Cardiovasc Surg 2021;161:44-5

$0022-5223 / \$ 36.00$

Copyright (c) 2019 Published by Elsevier Inc. on behalf of The American Association for Thoracic Surgery https://doi.org/10.1016/j.jtcvs.2019.10.051

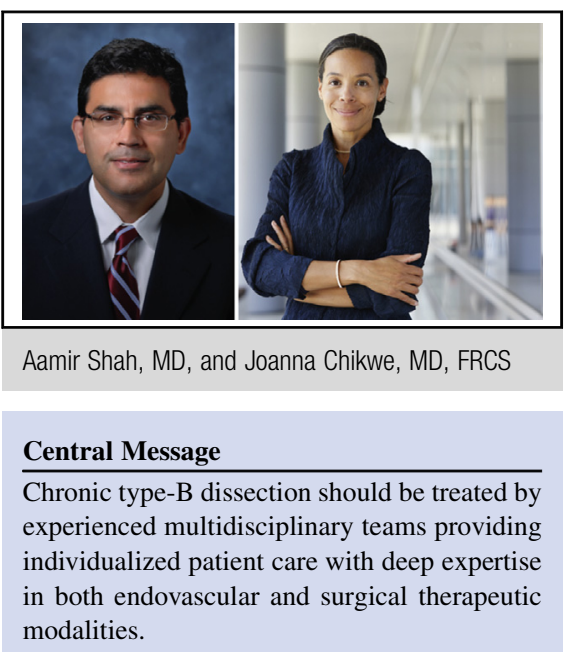

See Article page 36.
Open surgical repair has long been standard for patients with chronic type-B aortic dissection and aneurysmal degeneration. However, improving outcomes with thoracic endovascular aortic repair (TEVAR) in this setting are fueling debate over the optimal strategy. ${ }^{1-4}$

In response, Tanaka and colleagues ${ }^{5}$ describe 697 patients with distal aortic dissection who underwent open repair between 1991 and 2017, reporting outcomes in 427 $(61 \%)$ who were retrospectively adjudicated by the authors to have been anatomically eligible for TEVAR. Thirty-day mortality was $8.4 \%$, and the incidence of stroke and spinal cord injury was $4 \%$ and $5.2 \%$. Survival was $61 \%$ at 10 years. Renal dysfunction, chronic pulmonary disease, and previous surgery were predictors of 30-day mortality. In patients without those risk factors, 30-day mortality was $2.6 \%$ : the authors conclude that such patients are low-risk surgical candidates who may benefit from open repair. Unfortunately, no TEVAR comparison data are provided because of the "limited number" of such patients.

The primary goal of TEVAR in type-B dissection is to exclude the primary intimal tear, promoting false lumen thrombosis resulting in aortic remodeling and reduction in aortic diameter. A major concern with TEVAR in chronic type-B dissection is that remodeling may be more difficult to achieve reliably because the fibrotic intimal flap is much stiffer than in the acute setting, where aortic wall reapposition is relatively easily accomplished, and where TEVAR has become the preferred approach. However, in the INSTEAD (Investigation of Stent Grafts in Patients with Type B aortic dissection) trial, $91 \%$ of patients with stable chronic type-B dissection undergoing TEVAR at a median of 82 days following acute dissection achieved complete false lumen thrombosis, indicating successful aortic remodeling following TEVAR. ${ }^{6}$

Retrospective studies show early mortality less than 5\% and stroke and spinal cord injury rates of less than $3 \%$ after TEVAR for chronic type-B dissection, with authors concluding results are superior to open repair. ${ }^{1-4}$ In a systematic review of open versus endovascular repair for chronic type-B dissection involving more than 2000 patients, early mortality $(9.3 \%$ vs $2 \%)$, stroke $(4.5 \%$ vs $2.7 \%$ ), and spinal cord injury ( $5 \%$ vs $2.2 \%$ ) were significantly worse with open repair compared with TEVAR. ${ }^{3}$ Reintervention rates were greater after TEVAR $(20.2 \%$ vs 11.8), and 3-year survival was similar between the groups (open repair $79.9 \%$ vs TEVAR 91\%). As the authors indicate, long-term outcomes of TEVAR are unknown.

Based on these data, our approach is similar to that described by Bavaria and Burke ${ }^{4}$ in their recent editorial on chronic type-B dissection, recommending TEVAR in patients with "reasonable" life expectancy without connective tissue disorders, whenever anatomically feasible. Anatomic criteria include adequate $(>2 \mathrm{~cm})$ proximal and distal landing zones $<40 \mathrm{~mm}$ diameter with a majority of the visceral branches arising from the true lumen, and no pseudocoarctation.

In the absence of a TEVAR comparison group, Tanaka and colleagues' impressive surgical series represents a valiant rearguard defense against the endovascular vanguard. However, these complex patients are currently best served by a collaborative approach at experienced centers with multidisciplinary teams offering individualized care including expertise in both modalities-only 
high-quality comparative data from such groups can truly inform and advance the optimal treatment paradigm.

\section{References}

1. Conway AM, Khalil Q, Mondry LR, Stoffels GJ, Giangola G, Carroccio A. Outcomes of thoracic endovascular aortic repair for chronic aortic dissections. J Vasc Surg. 2018;67:1345-52.

2. Boufi M, Patterson BO, Loundou AD, Boyer L, Grima MJ, Loftus IM, et al. Endovascular versus open repair for chronic type B dissection: a meta-analysis. Ann Thorac Surg. 2019;107:1559-70.

3. Thrumurthy SG, Karthikesalingham BO, Holt PJE, Hinchliffe RJ, Loftus IM, Thompson MM. A systematic review of mid-term outcomes of thoracic endovas- cular repair (TEVAR) of chronic type B aortic dissection. Eur J Vasc Endovasc Surg. 2011;42:632-47.

4. Burke CR, Bavaria JE. The role of thoracic endovascular repair in chronic type B aortic dissection. Semin Thorac Cardiovasc Surg. September 4, 2019 [Epub ahead of print].

5. Tanaka A, Sandhu HK, Afifi RO, Miller CC III, Ray A, Hassan M, et al Outcomes of open repairs of chronic distal aortic dissection anatomically amenable to endovascular repairs. J Thorac Cardiovasc Surg. 2021;161: 36-43.e6.

6. Nienaber CA, Kische S, Akin I, Rousseau H, Eggebrecht H, Fattori R, et al. Strategies for subacute/chronic type B aortic dissection: the Investigation of Stent Grafts in Patients with Type B aortic dissection (INSTEAD) trial 1-year outcome. J Thorac Cardiovasc Surg. 2010;140:S101-8. 